\title{
LA RETÓRICA DEL MIEDO: MEMORANDO UN NEFASTO MEMORÁNDUM
}

\author{
Henry Campos Vargas* \\ A Ana Lucía López Villegas (Lucy) \\ Argumentar racionalmente es un privilegio de pocas culturas. \\ Para unos es una invención humana, \\ para la gran mayoría \\ una conquista de la humanidad.
}

\begin{abstract}
RESUMEN
Este artículo analiza, desde un punto de vista retórica y argumentativo un famoso memorando de Kevin Casas. En este documento, Casas recomendaba el empleo del temor en la lucha a favor del T.L.C.

Palabras clave: Temor, retórica, argumento, Kevin Casas, Óscar Arias.
\end{abstract}

\section{ABSTRACT}

This article analyse a famous Kevin Casas's memorándum from a rhetorical and argumentative point of view. In this document Casas recommended to use fear in the fight in favor of T.L.C.

Key Words: Fear, rhetoric, argument, Kevin Casas, Óscar Arias.

\section{Introducción}

El 7 de octubre del 2007, Costa Rica fue a las urnas convocada para su primer referéndum histórico, su objeto: aprobar o rechazar el proyecto de Ley de la República sobre el denominado Tratado de Libre Comercio entre República Dominicana, Centroamérica y los Estados Unidos (de aquí en adelante T.L.C. por antonomasia).

Las características propias del referéndum implicaron desde un inicio que todo el discurso alrededor del proyecto fuera binario. En efecto, no se presentaba a la ciudadanía la posibilidad de una tercera opción: desde un punto de vista lógico, regía el principio de tercero excluido. De esta manera, surgieron dos bloques: el llamado discurso del sí (que apoyaba la aprobación del proyecto) y el discurso del no (que proponía su rechazo).

Las siguientes reflexiones tratan de un polémico documento asociado al primero de esos grupos, ya que el gobierno del entonces Presidente de la República Dr. Óscar Arias Sánchez asumió un apoyo incondicional al proyecto de ley. Esta decisión era consistente con su política, ya que el contenido del futuro Tratado había sido el producto de la ingente labor de su 
equipo de negociadores. El texto fue firmado en un acto público oficial por los representantes de los gobiernos interesados, de manera que la decisión del equipo de gobierno de participar en la publicidad a favor del T.L.C. no era en absoluto reprochable: se había invertido tiempo, dinero, conocimiento y recursos en ello, además de que se concebía como una vía de desarrollo para la economía del país.

No es menester discutir si los Tratados de Libre Comercio son el instrumento adecuado para el desarrollo de Costa Rica: el problema es sumamente complejo y la información es difícil de procesar e interpretar.

El quid de esta reflexión versa sobre la retórica empleada en la estrategia publicitaria.

\section{Autoría del memorándum}

Durante el curso de la discusión, un evento particular marcó un hito: se trata de la difusión pública de un controversial memorándum, suscrito por el hasta ese entonces Segundo Vicepresidente de la República, Kevin Roberto Casas Zamora, y el diputado liberacionista Fernando Sánchez. Este documento expresaba de manera explícita la necesidad de que el gobierno de la República manipulara al electorado infundiéndole temor, con el único propósito de que votaran afirmativamente el T.L.C.

El texto completo fue publicado, entre otros medios, por el Semanario Universidad el 13 de setiembre del 2007, donde abarca las páginas 20 y 21. De acuerdo con el texto mismo, fue producto de una reunión efectuada en San Isidro de Heredia, de la cual surgieron varias recomendaciones. Confeccionado el 29 de julio del 2007, se dirigió al Presidente de la República y a su hermano Rodrigo Arias, quien ocupaba el cargo de Ministro de la Presidencia. Curiosamente, consta de nueve apartados, donde fácilmente podrían esperarse diez. Sobre este número Juan Eduardo Cirlot expresa:

Nueve: Triángulo ternario. Triplicidad de lo triple. Imagen completa de los tres mundos. Límite de la serie antes de su retorno a la unidad. Para los hebreos, el nueve era símbolo de la verdad, teniendo la característica de que multiplicado se reproduce a sí mismo (según la adición mística) (1997: 337).

La asociación del nueve con la verdad, en el contexto del presente memorándum, no deja de tener rasgos verdaderamente irónicos.

Las diversas acciones cuya materialización se recomendaba eran:

1. Establecer un comité de estrategia de la campaña del SÍ.

2. Construir una coalición social a favor del TLC.

3. Gestionar un receso en la Asamblea Legislativa.

4. Formalizar una alianza con los alcaldes municipales, particularmente los del PLN.

5. Oficializar el apoyo del PLN.

6. Estructurar y lanzar campaña masiva en medios de comunicación.

7. Generar gran cantidad de documentación impresa sobre el TLC y sobre la oposición, apta para ser repartida.

8. Organizar un programa sistemático de visitas a las empresas por parte de altos funcionarios del gobierno.

9. Organizar un acto multitudinario de fuerza para darle motivación a la campaña.

Tal y como puede apreciarse, se trata de un conjunto de lineamientos que, salvo los de carácter político-institucional (como el receso legislativo, los acuerdos con los alcaldes, así como el apoyo oficial del PLN y las visitas de gestores gubernamentales), están al alcance de cualquier movimiento proselitista y bien podrían considerarse acciones legítimas de una parte interesada en defender una tesis.

\section{Análisis del memorándum}

A pesar de las observaciones anteriores, el sexto apartado se ocupó de proponer un conjunto de medidas que atentan directamente contra cualquier esquema ético, político y 
argumentativo. Inicia con una variante de la captatio benevolentiae:

Más allá de lo que pueda hacer en las comunidades y en las empresas, es tan poco el tiempo que queda, que no hay que tener pudor alguno en saturar los medios de comunicación con publicidad. Y precisamente por el corto tiempo, es imperioso dirigir la campaña en dos direcciones (2007: 21).

Desde su presentación, este punto renuncia a aplicar los códigos de conducta que podrían considerarse normales. Así lo sugiere mediante el empleo de la voz pudor que, de acuerdo con la Real Academia de la Lengua Española, significa honestidad, modestia, recato (1992: 1688). En palabras de Christian Plantin:

La palabra tiene, pues, una doble función, designa y orienta, o, más bien: al designar las cosas de una determinada manera, la palabra revela la orientación del discurso. Lejos de ser un simple "elemento" del discurso, la palabra es, así, el holograma del discurso (2008: 103, la negrita es del original).

Esto es cierto para el presente caso, en el cual el uso de esta voz posee valor argumentativo, ya que al sugerir desde este momento del discurso la renuncia a principios stándard de comportamiento, muestra con claridad y "franqueza" su identidad, prepara el nivel de agresividad que se va a plantear, a la vez que pretende lograr un grado de comunión con los receptores. La comunión es uno de los efectos discursivos más importantes para Perelman y Olbrechts-Tyteca, al punto de constituir una de las tres principales figuras estudiadas por ellos (las otras dos son las figuras de elección y las de presencia). Las de comunión, tal y como su nombre sugiere,

son aquellas con las que por medio de procedimientos literarios, el orador se esfuerza por crear o confirmar la comunión con el auditorio. A menudo, esta comunión se obtiene gracias a las referencias a una cultura, una tradición o un pasado comunes (1989: 282, §42).

En este texto, la comunión se consigue merced al empleo del eufemismo pudor (en lugar de ética o escrúpulos, palabras que serían más groseras) y al interés en común: la aprobación del TLC.

El empleo de una figura retórica en la argumentación (como es el caso del eufemismo) es un fenómeno que ha sido estudiado también por Perelman y OlbrechtsTyteca, en su Tratado de la argumentación, la Nueva Retórica, quienes señalan:

Consideramos argumentativa una figura si, al generar un cambio de perspectiva, su empleo es normal en comparación con la nueva situación sugerida. Por el contrario, si el discurso no provoca la adhesión del oyente a esta forma argumentativa, se percibirá la figura como un ornato, una figura de estilo, la cual podrá suscitar la admiración, pero en el plano estético o como testimonio de la originalidad del orador (1989: 271, §41).

En virtud de esta perspectiva, afirman:

Para nosotros, que nos interesamos menos por
la legitimación del modo literario de expresión
que por las técnicas del discurso persuasivo, nos
parece importante, no tanto estudiar el problema
de las figuras en su conjunto, como mostrar en qué
y cómo el empleo de ciertas figuras determinadas
se explica por las necesidades de la argumentación
$(1989: 269, \S 40)$.

Esta renuncia no es caprichosa, ya que aparece justificada argumentalmente en el texto: es tan poco el tiempo que queda. En este enunciado es fácil identificar los componentes argumentativos expresados por Plantin, para quien

La argumentación es una operación que se apoya sobre un enunciado asegurado (aceptado) -el argumento- para llegar a un enunciado menos asegurado (menos aceptable) - la conclusión.

Argumentar es dirigir a un interlocutor un argumento, es decir, una buena razón para hacerle admitir una conclusión e incitarlo a adoptar los comportamientos adecuados (2008: 39).

La conclusión no hay que tener pudor está fundamentada en el argumento (razón) queda muy росо tiempo. Ahora bien, apunta Plantin, el tránsito de las "premisas" a la "conclusión" opera mediante una adecuada Ley de paso que permite que los datos que ofrece un interlocutor 
asuman el carácter de argumento de una tesis, de manera que esta última, adquiera el estatus de conclusión.

La ley de paso tiene la función de transferir a la conclusión la aceptación que se le atribuye al argumento. Este paso supone siempre un salto, una diferencia de nivel entre el enunciado del argumento y el enunciado de la conclusión (...) La ley de paso aporta a la premisa el sentido argumentativo que no tenía antes: éste es un postulado fundamental de la argumentación discursiva. De ahí toma la premisa su orientación hacia la conclusión. Expresa una verdad general, a veces de tipo proverbial, atribuida a un enunciador colectivo: "Se sabe que...". A menudo implícita, la ley de paso permite al argumentador apoyar lo que dice en un principio, en una convención admitida en su comunidad de habla. Estos principios reciben el nombre también de lugares comunes, o topoi (sing. topos) (2008: 42-43).

La ley de paso sobre la que se fundamenta este discurso es el principio la premura de tiempo justifica acciones extremas.

Dos son las direcciones hacia las que el memorándum recomienda dirigir la campaña en los medios de comunicación. Primero propone:

Desbancar la idea de que esta es una lucha de ricos contra pobres. Eso requiere escoger muy bien los rostros de la comunicación masiva del SÍ y utilizar casi exclusivamente trabajadores y pequeños empresarios.

Asimismo, debemos subirle muchísimo los decibeles y la presencia mediática y discursiva a la agenda social del gobierno (2007: 21).

Casas y Sánchez proponían en este punto modificar la percepción del contexto. De acuerdo con la crítica retórica,

Un texto puede presentar una percepción del contexto o una conciencia particular del mismo nombrando los acontecimientos, objetos y otros aspectos del contexto de un modo determinado (Gill y Whedbee, 2003: 247).

Se trata de una pretensión válida $\mathrm{y}$ legítima en toda argumentación política, como la discusión del T.L.C. Ahora bien,

Las actividades de los críticos retóricos en los últimos treinta años han sido bastante variadas; sin embargo, lo que tienen en común es la explicación de la interacción dinámica existente entre un texto retórico y su contexto, es decir, el modo en el que un texto refuerza, altera o responde a las opiniones de un público determinado, o del tejido social de la comunidad (Gill y Whedbee, 2003: 236).

Por esto, interesa identificar el juego de imágenes sugeridos en el memorándum. Es fácil apreciar que la acción comentada se dirige al grueso del electorado costarricense, no a la élite ni a la clase alta. El motivo: la votación sería decidida por este sector social, en virtud de su hegemonía numérica.

Aquí, mediante una retórica de la imagen, se pretende construir una elección discursiva para obtener la comunión con un auditorio específico, tal y como Perelman y OlbrechtsTyteca han explicado.

La segunda de las recomendación es, en cuanto a su enunciación, breve, pero su desarrollo es, tal y como se verá, prolijo. Consiste en:

Estimular el miedo. Ese miedo es de cuatro tipos (2007: 21).

Con esta afirmación inicia la retórica del miedo propuesta en tan nefasto memorándum.

En la discusión sobre el T.L.C. era inevitable que surgieran sentimientos de inseguridad, confusión e, incluso, temor, en el auditorio. Las implicaciones favorables y desfavorables de cualquier de las dos alternativas (su aprobación o improbación) eran muy serias. Ciertamente, casi en cualquier tipo de argumentación puede surgir el temor. Empero, jamás debe ser buscado premeditadamente como un recurso argumentativo.

El temor, tal y como expresa Gorgias en su Encomio a Helena afecta las facultades racionales, es decir, la capacidad crítica y analítica del ser humano, por lo que tiene implicaciones argumentativas:

Por otra parte hay quienes a causa de haber tenido visiones terroríficas, pierden instantáneamente el juicio a consecuencia de las mismas: hasta tal punto perturba y destruye a la mente el temor. $\mathrm{Y}$ muchos caen en absurdas enfermedades, en terribles penalidades y en incurables locuras: hasta tal punto la vista grabó en su espíritu las imágenes de las cosas contempladas. Y paso por alto muchos ejemplos de visiones espeluznantes, 
dado que son semejantes las que no cito a las ya indicadas (1966: 114).

Pero, además,

La verdad de esta argumentación se presenta como poderosa a causa del temor que se deriva de la percepción visual, la cual, una vez que se ha producido, hace que se renuncie a actuar, aunque se sepa lo que es bueno según la ley y lo que es justo según el derecho (ibid: 113).

De donde se colige que el temor afecta severamente la voluntad, elemento de fundamental importancia en una consulta popular. Esto, evidentemente, no solo contraviene normas lógicas, argumentativas y éticas, sino que merma cualquier posibilidad para una discusión crítica, entendida como aquélla cuyo

(...) propósito es lograr acuerdos acerca de la aceptabilidad o inaceptabilidad de los puntos de vista en discusión, averiguando si, mediante la argumentación, pueden o no ser adecuadamente defendidos de la duda o de la crítica (van Eemeren y Grootendorst 2002: 55).

De acuerdo con van Eemeren y Grootendorst, las discusiones de esta naturaleza poseen reglas. Ellos, en su obra Argumentación, comunicación y falacias - una perspectiva pragma-dialéctica, enuncian una serie de diez normas (a la que no denominan decálogo en ningún momento, dadas sus implicaciones moralizantes), que comprenden tanto las conocidas falacias lógicas como principios generales sobre la argumentación. Más adelante se podrán identificar las violaciones que a este respecto comportan los planteamientos del memorándum.

Los cuatro vértices del temor que explotaría la campaña serían:

i. Miedo a la pérdida de empleo.

ii. Miedo al ataque a las instituciones democráticas.

iii. Miedo a la injerencia extranjera en el NO.

iv. Miedo al efecto de un triunfo del NO sobre el Gobierno.
Desde un punto de vista semiótico, fueron considerados casi todos los elementos del discurso. La pérdida de empleo considera al auditorio. Por su parte, el efecto de un triunfo del NO sobre el Gobierno atiende al emisor. La injerencia extranjera en el NO puede asociarse con el mensaje (en este caso, del NO), mientras que el ataque a las instituciones democráticas bien puede identificarse con el canal.

No cabe duda de que el planteamiento, aunque contrario a toda ética, es muy completo.

El miedo a la pérdida de empleo se explicita así:

Aquí pareciera muy recomendable utilizar
intensivamente testimoniales de gente muy sencilla
y en situación precaria, que pueda perder el
empleo o ya lo perdió como consecuencia de la
no aprobación del TLC. Esto además es vital para
reforzar la idea de que esta no es una lucha de
ricos contra pobres. Del mismo modo, es posible
que en regiones específicas tenga un gran impacto
visibilizar los casos concretos de empresas que han
postergado inversiones, que han recortado turnos
o que se están considerando irse del país por la no
aprobación del TLC (2007: 21).

Examinar una tesis desde sus consecuencias es un recurso válido, lícito y necesario en toda discusión. Sin embargo, la manipulación de las emociones en el grado expuesto por el memorándum, constituyen serias y graves violaciones a los principios de una discusión crítica. Van Eemeren y Grootendorst consideran el tema de la manipulación de las emociones a propósito de las violaciones a las reglas 1 y 4 de su propuesta, las cuales nos hemos permitido denominar como infracciones a los principios de libertad y de pertinencia defensiva, respectivamente.

El principio de libertad, regla 1 para van Eemeren y Grootendorst, se enuncia de la siguiente manera:

Las partes no deben impedirse unas a otras el presentar puntos de vista o el ponerlos en duda (2002: 223).

Puede verse afectado de distintos modos:

Violaciones a la Regla 1 por el protagonista o por el antagonista, en la etapa de confrontación: 


\author{
1. Con respecto a los puntos de vista: \\ - prohibir puntos de vista \\ - declarar sacrosantos a ciertos puntos de vista
}

\section{Con respecto al oponente:}

- Presionar a la parte contraria por medio de la manipulación de sus sentimientos de compasión o amenazándolo con sanciones

- Hacer un ataque personal contra el oponente recurriendo a:

- presentarlo como estúpido, malo, poco confiable, etc.

. sembrar la sospecha sobre sus motivaciones.

- señalar una inconsistencia entre sus ideas y sus acciones, en el pasado $\mathrm{y} / \mathrm{o}$ en el presente (2002: 224).

Por su parte, el principio de pertinencia argumentativa, regla 4 de van Eemeren y Grootendorst, se enuncia en los siguientes términos:

Una parte solo puede defender su punto de vista presentando una argumentación que esté relacionada con ese punto de vista (2002: 223).

En relación con este principio, se apuntan las siguientes amenazas:

Violaciones a la Regla 4 por el protagonista, en la etapa de argumentación:

1. La argumentación no se refiere al punto de vista en discusión

- argumentación irrelevante

2. El punto de vista no se defiende por medio de una argumentación, sino empleando medios persuasivos no argumentativos

- Manipulando las emociones de la audiencia

- Enumerando las cualidades propias (2002: 225).

Estas reglas y violaciones, desde una perspectiva lógica, se relacionan con la falacia de apelación a la misericordia o argumentum ad misericordiam. van Eemeren y Grootendorst identifican dos variantes específicas de esta forma de argumentar. Por un lado, la presión hecha a la parte contraria mediante la manipulación de sentimientos de compasión (2002: 227), por otra, el tratar de ganarse el favor de la audiencias presentándose a sí mismo muy humildemente (2002: 229).

La naturaleza falaciosa de la publicidad propuesta es manifiesta: se manipularía la imagen y la situación laboral de gente muy sencilla y en situación precaria para asociarlas con la pérdida de empleo ante la falta de aprobación del T.L.C. Es muestra de la atávica retórica de los pobrecitos costarricense que mueve y aprovecha la compasión, burlando la razón, para arribar a la conclusión. Según van Eemeren y Grootendorst:

Debido a que esta técnica de restringir la libertad de la otra parte para presentar o criticar un punto de vista juega con sus sentimientos de compasión, este tipo particular de violación de la Regla 1 es llamado argumentum ad misericordiam. Tales intentos de especular con los sentimientos de lástima para silenciar al oponente y para lograr los propios fines son más comúnmente usados cuando una parte desea que la otra haga algo por ellas. Las sanciones usadas para respaldar tales amenazas van desde señalar las consecuencias desagradables que se producirán si el afectado no logra lo que quiere ("Si tú me fallas, me quitarán la beca") hasta los ataques de llanto, o cosas peores (2002: 130).

En el memorándum puede apreciase un hábil manejo de los medios al tratar de transformar la percepción del contexto, otro concepto desarrollado por la retórica crítica, ya que:

Un texto, además de operar para denominar el contexto, puede también operar para darle una nueva denominación (Gill y Whedbee, 2003: 247-248).

Esto sucede gracias al empleo de mecanismos retóricos de los que es pertinente tener conciencia:

Lo más importante, sin embargo, es que los críticos retóricos deben también confrontar el hecho de que no todos los individuos o grupos tienen igual acceso a los canales de comunicación, y de que el discurso no es benigno sino hegemónico; la retórica 
puede actuar como un medio de dominación y de opresión, como cuando, por ejemplo, se concentra en formas masculinas de comprensión y suprime, al mismo tiempo, las perspectivas femeninas. Todo texto, al concentrarse en ciertas cosas, al presentar al público ciertas cosas, simultáneamente, oscurece otras (Gill y Whedbee, 2003: 237).

Del modelo lucha de ricos contra pobres se pasa, no a una campaña a favor de los pobres, cuya credibilidad podría ser muy escasa (¿los ricos a favor de los pobres?), además de que fácilmente podría ser acusada de cínica, sino a una iniciativa para no perjudicar a los menos privilegiados. A través del manejo de la imagen de la clase trabajadora, se construye una especie de escudo que no permita apreciar otros intereses en juego.

Sin lugar a dudas, considerar cómo afectaría la generación de empleo la improbación del T.L.C. no solo es un argumento válido, sino necesario en una discusión democrática. Sin embargo, en este panorama, el voto negativo contra el T.L.C. sufriría una recriminación moral y culpabilizadora, de donde surge el carácter manipulador de la propaganda sugerida.

En la estrategia del SI, la imagen posee un valor eminentemente argumentativo. Posee una naturaleza mixta, ya que participa de rasgos testimoniales, pero también funge como exemplum (ejemplo). Si bien es cierto se escucha y presenta la voz de quienes han sufrido cierto tipo de consecuencias por la situación discutida, ya sea de trabajadores, ya de empresarios (aspecto testimonial), su aparición en escena pretende confirmar una tesis (aspecto ejemplar $\mathrm{y}$ argumentativo).

En su Manual de retórica, Bice Mortara Garavelli propone esta definición:

El ejemplo (gr. Parádeigma, "modelo"; lat. Exemplum) es la narración de un episodio con el fin de ratificar lo que se trata (...) Como elemento del ornatus, el ejemplo aparece en formas y dimensiones dispares, desde la antonomasia a la alusión y a la alegoría. Las colecciones de hechos memorables, piedra angular de la hagiografía (religiosa y laica) y de la catequesis de todo tiempo y civilización, utilizan los exempla sistemáticamente (1988: 289).

Sobre la argumentación por ejemplo la autora citada indica:
(...) suele utilizar el procedimiento inductivo de la generalización para llegar a conclusiones cuya validez es sólo particular; es la llamada "argumentación de lo particular a lo particular" (semejante o idéntica al razonamiento por analogía). De una situación concreta que se toma como ejemplo, se deriva una regla aplicable a otra situación concreta: "he tardado media hora en ir en coche de casa a la estación a las nueve de la mañana; tardaré más de media hora (en vez de los diez minutos previstos) en un trayecto por la ciudad, a la misma hora, si éste incluye el camino de mi casa a la estación" (1988: 87-88).

La tradición aristotélica a este respecto es elocuente. El ejemplo es uno de los tipos de pruebas por persuasión (el otro es el entimema, en este sentido Aristóteles 1999: 1356b8) que opera por inducción, ya que

(...) demostrar a base de muchos casos semejantes es, allí, una inducción y, aquí, un ejemplo; mientras que obtener, dadas ciertas premisas, algo diferente de ellas, por ser $<$ tales premisas $>$, universalmente o la mayor parte de las veces, tal como son, eso se llama, allí, silogismo y, aquí, entimema (1999: 1356b15-18, 180-181).

Para Aristóteles, los ejemplos establecen una relación

(...) de la parte con la parte y de lo semejante con lo semejante: cuando se dan dos <proposiciones> del mismo género, pero una es más conocida que la otra, entonces hay un ejemplo, como cuando $<$ se afirma que $>$ Dionisio, si pide una guardia, es que pretende la tiranía. Porque, en efecto, como con anterioridad también Pisístrato solicitó una guardia cuando tramaba esto mismo y, después que la obtuvo, se convirtió en tirano, e igual hicieron Teágenes en Mégara y otros que se conocen, todos estos casos sirven de ejemplo en relación con Dionisio, del que todavía no se sabe si la pide por eso. Por consiguiente, todos estos casos quedan bajo la misma proposición universal de que quien pretende la tiranía, pide una guardia (1999: 1357b29-37, 188-189).

En el caso sub exámine, a través del "testimonio" de un conjunto de afectados, se pretende obtener una generalización: si no se aprueba el T.L.C. mucha gente perderá su trabajo. La validez relativa de este enunciado (ya que muchas personas pierden su trabajo todos los días, no a causa de la aprobación o no de un tratado de libre comercio, sino por la dinámica 
de la economía de mercado o por muchas otras razones), se pretende transformar en una validez universal, lo cual es un error lógico.

Por su parte, el miedo al ataque a las instituciones democráticas, de acuerdo con el memorándum, consiste en lo siguiente:

Es crucial convertir al SI en equivalente con la
democracia y la institucionalidad (es lo que decía
Eduardo Ulibarri: hay que ir llenando al SI de
un contenido de valores) y al NO en equivalente
de la violencia y la deslealtad con la democracia.
Aquí hay algo muy importante: esta campaña ya
dejó de ser racional y, en consecuencia, sobre
el contenido del TLC. Así, el argumento de la
defensa de la democracia es el único recurso que
nos queda para movilizar la emoción de la gente
que está a favor del TLC. En este momento la
gente que está a favor no sólo no tiene motivación
alguna, sino que se siente intimidada por la
motivación que muestra la gente del NO. Hay que
entender una cosa: nadie está dispuesto a "morir"
por el libre comercio. Pero tal vez sí por la
democracia. Hay que darle una motivación ética
y no sólo instrumental al SI (2007: 21 ).

En efecto, por desgracia, la discusión en relación con la aprobación del T.L.C. no fue racional y era sumamente difícil que lo fuera. $\mathrm{La}$ cita goza de relevancia en virtud de testimoniar que mucha de la gente del SI se siente intimidada por la motivación que muestra la gente del NO. Tal y como se aprecia, no se denuncian acciones intimidantes por parte de los defensores de la tesis contraria, sino, más bien, una especie de reacción frente a lo que el texto denojmina motivación, aunque más bien se asemeja a la convicción de la gente del NO. Esta convicción se encontraba probablemente aparejada con fuertes argumentos (no necesariamente racionales) que cuestionaban seriamente a la masa del SI, con las repercusiones citadas.

El apartado noveno del memorándum reiteraba este problema con el título Organizar un acto multitudinario de fuerza para darle motivación a la campaña:

Existe gran desmotivación entre quienes están a favor del TLC, desorientación por la ausencia de una campaña y, en muchos casos, miedo de expresar las opiniones. Hay que motivar a los partidarios del SI, hacerles sentir que la campaña está haciendo cosas, que no están solos, que somos muchos. Es recomendable organizar un acto público o un festival multitudinario (podría ser una marcha, pero ahí casi siempre tenemos problemas). Pero la gente tiene que sentirse acompañada y motivada (2011: 21).

Esta sección de la propuesta rescata también la dimensión llamada en el texto ética de la argumentación. En realidad, refleja cierto nivel de conciencia respecto de que la argumentación involucra escalas de valores. $\mathrm{Si}$ bien no todos los valores son de contenido ético (piénsese en los valores de comercio, los de calidad, de conveniencia...), estos desempeñan un papel preponderante en el razonamiento natural que debe ser ponderado en virtud del carácter enciclopédico de la mente humana.

Como parte de su manejo de la percepción del contexto, proponen asociar la defensa del T.L.C. con una defensa de las instituciones democráticas del país. Es parte de los denominados procesos de elección (Perelman y Olbrechst-Tyteca emplean el término figuras, sobre el tema puede consultarse 1989: 274 ss.), en los que el emisor emplea diversos instrumentos retóricos al plantear su punto de vista. Aquí estaría involucrada ya sea la definición oratoria, ya la perífrasis, a través de las cuales se establecería este nexo sustancial entre el Sí y la democracia.

Simultáneamente opera también un proceso de comunión, donde

(...) por medio de procedimientos literarios, el orador se esfuerza por crear o confirmar la comunión con el auditorio. A menudo, esta comunión se obtiene gracias a las referencias a una cultura, una tradición o un pasado comunes (Perelman y Olbrechst-Tyteca, 1989: 282).

Para los suscriptores del memorándum, esa cultura, tradición y pasado comunes están representados por el espíritu democrático. El procedimiento es sumamente efectivo, ya que es más fácil vincular lógicamente la aprobación (en realidad, discusión) de un T.L.C. con procesos democráticos, en lugar de demostrar que el rechazo a un T.L.C. debilita dicha forma de gobierno.

Ahora bien, evidentemente, en la medida que este vínculo de conceptos e imágenes es 
débil, la argumentación es capciosa y falaz. Bien podría tratarse de una falacia de conclusión inatingente, ya que la tesis y conclusión propuestas se enunciarían como defender el T.L.C. es defender la democracia. Es claro que no existe una regla de paso clara y sólida para fundamentar este razonamiento. Para van Eemeren y Grootendorst, se trata de una nueva infracción a la regla 4, nuestro principio de pertinencia argumentativa, dado que la relación entre la argumentación y el punto de vista es extremadamente débil.

Un manejo semejante de la imagen, aunque en este caso se trata de la imagen del NO, se presenta en el índice iii de este apartado:

\section{iii. Miedo a la injerencia extranjera en el NO.} Hay que restregar por todas partes la conexión del NO con Fidel Castro y Ortega, en términos bastantes (sic) estridentes. Es posible que este tipo de campaña pueda incomodar a alguna gente, pero es casi seguro de que puede tener un impacto considerable entre la gente más sencilla, que es donde tenemos los problemas más serios (2007: 21).

El error de esta estrategia reside en la manipulación que pretende desarrollar. Pese a ello, la argumentación es en gran medida válida, toda vez que la denuncia de intereses extranjeros en una discusión democrática no es un tema que resulte ajeno a la discusión.

No se trata de la falacia personal, circunstancial o no, sino de información que es de suma relevancia aclarar o denunciar en la discusión. Sobre el tema, van Eemeren y Grootendorst escriben:

Reconocer la relevancia de tales acusaciones de falta de conocimiento o de falta de incorruptibilidad no constituye una excepción a la regla básica de que el oponente no puede ser eliminado mediante el ataque personal. En un caso como este, una referencia a su persona es, después de todo, parte del contenido proposicional del punto de vista que está en discusión y los comentarios acerca de ella son, en principio, argumentos relevantes en la discusión. Si fueran prohibidos, se haría imposible, desde el principio, lograr una resolución de la disputa. ¿Cómo se podría mostrar que alguien es deshonesto si a uno no se le permite dar ejemplos de su falta de honestidad? (2002: 133).
Esto tiene serias consecuencias, en particular respecto de la credibilidad del autor, que es uno de los factores que la crítica retórica examina a propósito del contexto de un documento:

La autoridad que los oradores y escritores poseen debido a su posición en el gobierno o en la sociedad, a sus acciones previas, o a su fama de eruditos, genera expectativas y afecta el funcionamiento de un texto. Esas características y calificaciones generales para hablar o escribir influyen en la manera de entender el texto y en el efecto que este tiene sobre el público (Gill y Whedbee, 2003: 244).

Este procedimiento es de raigambre muy antigua. Ya Aristóteles había examinado la importancia retórica de lo que él denominó ethos y que incluso llegó a identificar como un tipo de argumentación.

El memorándum explota otro de los conceptos que los críticos retóricos ponderan a propósito del contexto de un discurso: la audiencia.

Para un crítico retórico es igualmente importante identificar la audiencia real a la cual se dirige el discurso. El crítico debe estar alerta con respecto al hecho de que aquellos que se encuentran inmediatamente próximos al orador pueden o no representar el auditorio al que este realmente se dirige (Gill y Whedbee, 2003: 241).

En este apartado, dicho auditorio está conformado por la gente más sencilla. En cambio, en el anterior eran los partidarios del Sí. No obstante, en uno u otro caso el efecto de la propaganda siempre redunda en beneficio del Sí, ya que la retórica del temor posee efectos tanto ad extra del grupo que ejerce el poder de la palabra como ad intra: en este último caso, refuerza el sistema de valores y creencias de sus integrantes. En este sentido, la propuesta en torno al referéndum confirma a sus adeptos en la creencia de que están en lo correcto al "defender" la generación de empleo, al "defender" la democracia y al "defender" la soberanía nacional ante la imagen amenazadora de Fidel Castro y Daniel Ortega.

El cuarto y último componente en el elenco de recomendaciones a favor del Sí consiste en: 
Miedo al efecto de un triunfo del NO sobre el Gobierno. Todas las encuentras detectan un grado importante de satisfacción con el Presidente y el Gobierno. Mucha gente simplemente no ha hecho la conexión de que un triunfo del $\mathrm{NO}$ en el referéndum, dejará al Gobierno en una posición precaria, con su efectividad totalmente reducida, y al país en una situación de ingobernabilidad. Esa conexión hay que inducirla. Este es un argumento que puede que solo funcione para ciertos sectores, pero puede ser muy efectivo sembrando la duda. Hay tres preguntas que debemos sembrar en la mente de la gente, que pueden hacer que les tiemble el dedo si están pensando votar por el NO:

1. ¿Están dispuestos a poner en riesgo la estabilidad económica, que casi todo el mundo reconoce como un logro del gobierno?

2. ¿Están dispuestos a volver a la época de Abel, cuando no gobernaba nadie, no había ningún sentido de rumbo y no pasaba nada en el país?

3. ¿Han pensado quién va a mandar en el país si gana el NO? (Respuesta inducida para la pregunta: van a mandar Albino, Merino, Carazo, etc.) (2010: 21).

Como se ha indicado supra, desde una perspectiva semiótica aquí se atiende al emisor del mensaje. Con una hábil asociación de conceptos se involucra al auditorio a través de la posible pérdida de los beneficios que el Gobierno le ha reportado. Al segmentarse en distintos conjuntos los miembros del colectivo social en función del grado de afectación por el rechazo al T.L.C. podía identificarse claramente un grupo de personas directamente afectadas (quienes perderían sus fuentes de trabajo o sus empresas), sin embargo, respecto de los que no verían una incidencia directa en su modo de vida podían descubrir mediante los recursos segundo, tercero y cuarto que no les era indiferente el rechazo del entonces proyecto de ley.

Este recurso involucra tanto la credibilidad del orador (aquí, el Gobierno) como la percepción del contexto, donde, a través de la $d u d a$ se siembra el temor con un claro efecto argumentativo: se procura obtener una conducta del elector, que vote afirmativamente el T.L.C.

Las tres últimas propuestas están sintetizadas en el apartado 3 de la sección 7 (Generar gran cantidad de documentación impresa sobre el TLC y sobre la oposición, apta para ser repartida), cuando se recomienda producir documentación del siguiente tipo:

La que siembre cizaña sobre los líderes, métodos, financiamiento y vínculos internacionales del $\mathrm{NO}$ (2011: 21)

Nuevamente la manipulación procura extenderse a todas las variables retórica y semióticamente relevantes.

\section{A manera de conclusión}

Aunque algunas de las propuestas sugeridas en el memorándum respecto de la defensa del Sí son válidas, es evidente que predomina la manipulación del contexto, las imágenes $\mathrm{y}$, en general, de las emociones del electorado a través del miedo.

\section{Epílogo}

Corolario de las reacciones y el escándalo suscitado por la publicación de este memorándum, el segundo Vicepresidente de la República, Kevin Casas, presentó su renuncia el 22 de septiembre del 2007. El Tribunal de Ética del Partido Liberación Nacional, al cual pertenece Casas, lo exoneró de toda responsabilidad, basado en la "ilegal" obtención del memorándum (Murillo 2009). El Juzgado Penal del Segundo Circuito Judicial de San José, desestimó una acusación contra Casas por los supuestos delitos de coacción y tráfico de influencias, se fundamentó en

\footnotetext{
Al acoger la tesis de que el documento fue sustraído, y que el mismo no ordena ni hace, viene a constituir el contenido de un pensamiento, de la manifestación de la libre autodeterminación del individuo (Mata 2009a).
}

También fue exonerado de la acusación de supuesta parcialidad y participación política prohibida promovida ante el Tribunal Supremo de Elecciones (Mora 2008).

Por su parte, respecto del exdiputado Fernando Sánchez, primo en segundo grado del expresidente Óscar Arias, el 17 de agosto del 2009, el Congreso de la República se declaró incompetente para conocer sobre su actuación en el memorándum (Mata 2009b). 
De acuerdo con un estudio efectuado, el $40 \%$ de los electores tuvo conocimiento de la existencia del memorándum (Villalobos 2007).

Los periodistas del Semanario Universidad, Lorna Chacón y Vinicio Chacón, fueron galardonados con el premio Jorge Vargas Gené en las categoría de defensa del derecho a la información y libertad de expresión por la publicación de este memorándum (Solano B. 2008).

Por último, el Tratado de Libre Comercio entre República Dominicana, Centroamérica y los Estados Unidos fue aprobado por 805.658 votos a favor, contra 756.814 de la oposición (Tribunal Supremo de Elecciones 2007: 1). Es Ley de la República No. 8622 de 21 de diciembre del 2007.

\section{Bibliografía}

Aristóteles. (1999). Retórica. Introducción, traducción y notas por Quintín Racionero. 2a reimpresión. Madrid: Editorial Gredos.

Cirlor, Juan Eduardo. (1997). Diccionario de símbolos. Ediciones Siruela, S. A. Madrid.

Gill, Ann M. y Whedbee, Karen. (2003). Retórica. En Teun A. van Dijk (Ed.), El discurso como estructura y proceso. Estudios sobre el discurso I. Una introducción multidisciplinaria. $2 \mathrm{a}$ reimpresión (pp. 233-270). Barcelona: Editorial Gedisa, S. A.

Gorgias (1966). Testimonios y fragmentos. Buenos Aires: Editorial Aguilar.

Mortara Garavelli, Bice. (1988). Manual de retórica. $3^{\mathrm{a}}$. Edición. Madrid: Ediciones Cátedra.

Mata, Esteban. (2009a). Juzgado desestima causa en contra de Kevin Casas. Extraído el 2 de septiembre del 2011 del sitio web: http://wvw.nacion.com/ln ee/2009/ abril/20/pais1939039.html

Mata, Esteban. (2009b). Congreso archiva caso de memorando por TLC. Extraído el 2 de septiembre del 2011 de: http:// wVw.nacion.com/ln_ee/2009/agosto/17/ pais2062060.html.

Mora, Ana Lupita. (2008). TSE exonera a Kevin Casas de beligerancia. Extraído el 2 de septiembre del 2011 del sitio web: http:// wvw.nacion.com/ln_ee/2008/mayo/31/ pais1558880.html

Murillo, Álvaro. (2009). PLN libera de culpa por memorando a Kevin Casas. Extraído el 2 de septiembre del 2011 del sitio web: http://wvw.nacion.com/ln_ee/2009/ agosto/26/pais2070148.html

Perelman, Ch. y Olbrechts-Tyteca, L. (1989). Tratado de la argumentación. La Nueva Retórica. $1^{\mathrm{a}}$. Reimpresión. Madrid: Editorial Grados, S. A.

Plantin, Christian. (2008). La argumentación. Barcelona: Editorial Ariel, S. A.

Real Academia de la Lengua Española. 1992. Diccionario de la Lengua Española. h/z. $21^{\text {a }}$ edición. Madrid: Editorial Espasa Calpe, S. A.

Solano B. Andrea. (2008). "Semanario Universidad" gana premio por publicar memorando. Extraído el 2 de noviembre del 2011 del sitio web: http://wvw. nacion.com/ln_ee/2008/septiembre/23/ aldea1710668.html.

Tribunal Supremo de Elecciones. (2007). No. 2944-E-2007 de las 14:30 horas del 22 de octubre del 2007. Extraído el 5 de diciembre del 2011 del sitio web: http://www.tse. go.cr/referendum2007_declaratoria.htm. 
Van Eemeren, Frans H. y Grootendorst, Rob. (2002). Argumentación, comunicación $y$ falacias. Una perspectiva pragmadialéctica. $2^{\mathrm{a}}$ edición. Ediciones Universidad Católica de Chile: Santiago, Chile.

Villalobos, Carlos. (2007). El 40\% de los electores supo del memorando. Extraído el 10 de agosto del 2011 de: http://wvw.nacion.com/ ln_ee/2007/octubre/04/pais1264012.htm.

\section{ANEXO}

Memorándum

Para: Presidente de la República, Ministro de la Presidencia

De: Kevin Casas, Fernando Sánchez

Fecha: 27 de julio del 2007

Asunto: Algunas acciones urgentes para activar la campaña del SI al TLC

Estimados don Óscar y don Rodrigo:

Luego de una larga conversación el día 27, tras participar en un debate sobre el TLC en San Isidro de Heredia, una actividad que resultó muy reveladora, hemos decidido hacerles este memorándum, que puntualiza algunas acciones que estimamos convenientes para activar cuando antes la campaña a favor del TLC. Evidentemente, no son las únicas que habría que hacer, pero pensamos que son importantes.

\section{Establecer un comité de estrategia de la campaña del SI}

Esto es quizá lo más urgente de todo. En este momento hay una orientación clara de qué es lo que hay que hacer para ganar, cómo hacerlo y con quién. Pero, peor aún, no hay un mecanismo establecido para tomar decisiones (o la ausencia de ellas). Tomadas por el grupo de comunicación, lo que claramente es insuficiente. Es esencial que el Presidente de la República y el Ministro de la Presidencia formen parte de este comité.

\section{Construir una coalición social a favor del TLC}

Aquí transcribimos lo que uno de nosotros escribió hace ya casi 3 años en un memorándum dirigido a Marco Vinicio Ruiz. El debate no lo va a ganar el gobierno ni lo van a ganar los empresarios solos, pero lo puede ganar una coalición. Uno de los graves errores que han cometido los sectores favorables al TLC ha sido delegar su defensa en los negociadores del acuerdo y, en general, en el gobierno. Aun antes de los recientes escándalos, que han minado la confianza en el estamento político, los niveles de credibilidad del gobierno eran ya muy bajos y probablemente insuficientes para conferir legitimidad a un proyecto tan controversial. En este momento nadie le cree una palabra al gobierno ni a los políticos y por ello sería una locura delegarles la función de defender el tratado. Formar una coalición y hacer que la defensa del TLC sea una obra colectiva es crucial no solo para superar esta tara de legitimidad, sino para evitar que la discusión acuse al mismo desbalance que fue ampliamente visible durante el conflicto del "combo" en el año 2000, cuando la organización de los opositores no tuvo más contrapeso que la voz solitaria del gobierno. Es vital demostrar que en la discusión sobre el TLC hay dos bloques amplios de interés, y eso supone que los sectores favorables- que tienen intereses nada difusos y tan intensos como los de los opositores- deben ser organizados y articulados. Esto es esencial para que la discusión sobre el TLC no corra con la misma suerte del "combo".

La importancia de este punto no puede soslayarse. La campaña sobre el TLC se está convirtiendo en lo que nunca debimos haber dejado que se convirtiera: una lucha entre ricos y pobres, y entre pueblo y gobierno. La coalición que tenemos en contra es formidable: universidades, Iglesia, sindicatos, grupos ambientalistas, etc. Y del otro lado, a favor del TLC, solo están el gobierno $\mathrm{y}$, a medias, los grandes empresarios. Así no hay forma de ganar. Es urgentísimo meter en la campaña, por lo menos, a los pequeños empresarios, a los solidaristas y a los 
que se puedan del cooperativismo. Y cuando decimos en la campaña es, simplemente, que "aparezcan" por todo lado las caras de algunos de sus líderes. Obviamente, si esos líderes además pueden efectivamente controlar parte de esos movimientos sociales, pues tanto mejor. Cierto es que en el solidarismo, en particular, no hay liderazgos nacionales fuertes. Si es así habrá que crearlos ya. Hay que darles presencia en medio a algunas caras del solidarismo y ello mismo los irá convirtiendo el líderes. ¿Quién era Eugenio Trejos en el país hace 6 meses? Es la exposición en medios la que lo ha convertido en un líder nacional.

\section{Gestionar un receso en la Asamblea Legislativa}

La campaña necesita, con urgencia, presencia de todas las comunidades del país. Dictar un receso en la Asamblea Legislativa es clave para sacar a nuestros diputados -que son más que los de oposición y que no enfrentan ninguna limitación para hacer campaña- a las comunidades, para organizar la campaña "de a pie". Es evidente que esto puede tener algún costo para el avance de la agenda legislativa, pero en este momento ese es un problema de tercer orden. Lo primer es, evidentemente, ganar el referéndum. En todo caso, en este momento la agenda legislativa no está caminando por falta de quórum. Eso nos deja en el peor de los mundos: la prensa hace al PLN responsable de la falta de quórum, mientras la oposición (y aun muchos de nuestros "aliados") no es vista como responsable y anda haciendo campaña. Además, la continuación de las negociaciones en sede legislativa nos expone a constantes chantajes de nuestros "aliados" legislativos, que terminan reflejándose en la campaña del SI.

\section{Formalizar una alianza con los alcaldes municipales, particularmente los del PLN}

Esto es decisivo y por similares razones que lo anterior: necesitamos presencia en todo el país. Existe una carta firmada por 72 alcaldes que no es, en absoluto, desdeñable. En ella, ofrecen su apoyo al TLC, pidiendo, como es enteramente esperable, algunas cosas a cambio. El contenido de la carta tiene elementos descartables, otros enteramente negociables y otros francamente positivos para el gobierno (por ejemplo, el apoyo explícito que ofrecen para la reforma tributaria). Es vital responder adecuadamente a esa carta, responder pronto y responder en un gran acto público.

Pero hay que hacer algo más, particularmente con los 59 alcaldes del PLN. Hay que hacerlos responsables de la campaña en cada cantón y transmitirles, con toda crudeza una idea muy simple: el alcalde que no gana su cantón el 7 de octubre no va a recibir un cinco del gobierno en los próximos 3 años. El mismo razonamiento puede aplicarse a los regidores, a quienes se puede hacer responsables de distritos específicos. En este último caso hay que recordarles sus aspiraciones personales: de ganar el referéndum depende que tengan posibilidades reales de seguir siendo regidores o de llegar a ser alcaldes o diputados. Ello no solo porque el desempeño del PLN en la próxima elección se verá muy afectado por el resultado del referéndum, sino porque esta elección va a servir para que las autoridades superiores del PLN calibren quién tiene madera de dirigente y quién no. Muchos dirigentes locales no se están metiendo en la campaña para no "quemarse" antes de la próxima elección. El razonamiento tiene que ser exactamente el contrario: el que no se mete de lleno, se "quema".

Lo que está en la base de esto es un asunto más profundo e importante: es urgente extender el círculo de la gente que está "jugando el pellejo" en este referéndum. En este momento existe entre nuestros aliados-dentro y fuera del PLN- una actitud generalizada de indolencia, como si pensaran que el único afectado por una derrota sería el Presidente. Es vital que entiendan que ellos van a salir directa y gravemente perjudicados. 


\section{Oficializar el apoyo del PLN}

Para construir una coalición social antes referida nos queda, desafortunadamente muy poco tiempo. Lo que tenemos en la mano es algo bastante menos potable, pero útil: una coalición política. Y eso implica meter de lleno al PLN, que es, por mucho, el actor más importante de esa coalición. Con excepción de la fracción legislativa, hasta ahora el papel de los órganos del PLN a favor del TLC, ni una directriz clara hacia la estructura del partido. Eso ha creado una gran confusión en la dirigencia, que sabe bien, además, que hay una parte del partido que está contra el TLC. La estructura oficial del PLN (Directorio, Comité ejecutivo) tiene que salir hablando inequívocamente en defensa del TLC, en el entendido de que uno de los principales ganadores o perdedores del referéndum va a ser el PLN.

\section{Estructurar y lanzar campaña masiva en medios de comunicación}

Más allá de lo que pueda hacer en las comunidades y en las empresas, es tan poco el tiempo que queda, que no hay que tener pudor alguno en saturar los medios de comunicación con publicidad. Y precisamente por el corto tiempo, es imperioso dirigir la campaña en dos direcciones:

1. Desbancar la idea de que esta es una lucha de ricos contra pobres. Eso requiere escoger muy bien los rostros de la comunicación masiva del SI y utilizar casi exclusivamente trabajadores y pequeños empresarios. Asimismo, debemos subirle muchísimo los decibeles y la presencia mediática y discursiva a la agenda social del gobierno.

2. Estimular el miedo. Ese miedo es de cuatro tipos.

i. Miedo a la pérdida de empleo. Aquí pareciera muy recomendable utilizar intensivamente testimoniales de gente muy sencilla y en situación precaria, que pueda perder el empleo o ya lo perdió como consecuencia de la no aprobación del TLC. Esto además es vital para reforzar la idea de que esta no es una lucha de ricos contra pobres. Del mismo modo, es posible que en regiones específicas tenga un gran impacto visibilizar los casos concretos de empresas que han postergado inversiones, que han recortado turnos o que se están considerando irse del país por la no aprobación del TLC.

ii. Miedo al ataque a las instituciones democráticas. Es crucial convertir al SI en equivalente con la democracia y la institucionalidad (es lo que decía Eduardo Ulibarri: hay que ir llenando al SI de un contenido de valores) y al NO en equivalente de la violencia y deslealtad con la democracia. Aquí hay algo muy importante: esta campaña ya dejó de ser racional y, en consecuencia, sobre el contenido del TLC. Así, el argumento de la defensa de la democracia es el único recurso que nos queda para movilizar la emoción de la gente que está a favor del TLC. En este momento la gente que está a favor no sólo no tiene motivación alguna, sino que se siente intimidada por la motivación que nuestra la gente del No. Hay que entender una cosa: nadie está dispuesto a "morir" por el libre comercio. Pero tal vez si por la democracia. Hay que darle una motivación ética y no sólo instrumental al SI.

iii. Miedo a la injerencia extranjera en el NO. Hay que restregar por todas partes la conexión del No con Fidel Castro y Ortega, en términos bastantes estridentes. Es posible que este tipo de campaña pueda incomodar a alguna gente, pero es casi seguro de que puede tener un impacto considerable entre la gente más sencilla, que es en donde tenemos los problemas más serios.

iv. Miedo al efecto de un triunfo del NO sobre el Gobierno. Todas las encuestas detectan 
un grado importante de satisfacción con el Presidente y el Gobierno. Mucha gente simplemente no ha hecho la conexión de que un triunfo del No en el referéndum, dejará al Gobierno en una posición precaria, con su efectividad totalmente reducida, y al país en una situación de ingobernabilidad. Esa conexión hay que inducirla. Este es un argumento que puede que solo funcione para ciertos sectores, pero puede ser muy efectivo sembrándola duda. Hay tres preguntas que debemos sembrar en la mente de la gente, que pueden hacer que les tiemble del dedo si están pensando votar por el NO:

1. ¿Están dispuestos a poner en riesgo la estabilidad económica, que casi todo el mundo reconoce como un logro del gobierno?

2. ¿Están dispuestos a volver a la época de Abel, cuando no gobernaba nadie, no había ningún sentido de rumbo y no pasaba nada en el país?

3. ¿Han pensado quién va a mandar en el país si gana el NO? (Respuesta inducida para la pregunta: van a mandar a Albino, Merino, Carazo, etc.)

Asimismo es muy importante fortalecer la presencia en la radio (tanto nacional como local) y en los medios rurales escritos, donde tenemos grandes problemas. Hay que poner a funcionar baterías en todos los programas de opinión y mejorar la pauta publicitaria del gobierno en una serie de programas de radio, conducidos por gente que tiene toda la disposición de ayudar al gobierno. (p.e. Javier Rojas, Jaime Peñas, etc.) Si la presencia del SI en radio no mejora drásticamente, esto seguirá manifestándose en nuestra debilidad en las zonas rurales. Es muy posible que los problemas que tenemos en zona rural tengan menos que ver en el fondo de la campaña (temas mal atendidos o desatendidos por esta) y más con la forma en que la gente se informa en zona rural, donde la radio es un medio de información muy poderoso.

\section{Generar gran cantidad de documentación impresa sobre el TLC y sobre la oposición, apta para ser repartida.}

Un problema serio que tenemos quienes estamos haciendo proselitismo a favor del TLC es la ausencia total de documentación de fácil digestión, que pueda circular masivamente. Como ya es sabido, ese es un punto que el NO ha desarrollado particularmente bien. En este momento tienen empapelado el país con volantes. La documentación que hay que hacer es de tres tipos:

1. La que aclare, en lenguaje muy simple, algunos de los argumentos más insidiosos contra el TLC (medicina, agua, celulares, etc). Como parte de esto, es muy importante que algunas instituciones clave (p.e. ICE, CCSS; AYA; MTSS) generen oficialmente volantes que contesten en términos muy contundentes los volantes que están siendo repartidos en sus propias instalaciones por los sindicatos de las instituciones. Se trata de volantes de información, que no pueden, en forma alguna, pedir el apoyo para el TLC (eso debido a la resolución del TSE)

2. La que exponga los efectos de un rechazo al TLC sobre sectores o aspectos específicos. (p.e las láminas de la presentación que usa Jorge Woodbridge).

3. La que siembra cizaña sobre los líderes, métodos, financiamiento y vínculos internacionales del NO.

\section{Organizar un programa sistemático de visitas a las empresas por parte de altos funcionarios del gobierno}

En este momento el espacio de proselitismo más fácil de aprovechar y el que nos ofrece las mejores oportunidades es por mucho, el de las empresas. Ahí hay más de un millón de trabajadores. Debemos organizar un esfuerzo sistemático de visitas a las empresas 
más grandes del país, con charlas a favor del SI impartidas por personas de alto nivel y con documentación en la mano. Ningún esfuerzo de proselitismo es potencialmente tan efectivo como este. Idealmente eso supone cinco pasos:

1. Disponer de la información de cuáles son y dónde están las empresas más grandes;

2. Que la campaña contacte a los empresarios para que concedan un espacio para la charla;

3. Que la empresa envíe de inmediato una carta al Ministerio de Planificación pidiendo el gobierno le envíe un representante para hablar del Plan Nacional de Desarrollo o de la visión futura del país algo por el estilo (eso para cubriros las espaldas de cara al TSE).

4. Armas un programa de visitas a empresas para, al menos, 30 jerarcas de gobierno;

5. El jerarca visita la empresa (en algunos casos acompañados por el diputado de la zona) y deja documentación.
Si 30 funcionarios visitan 10 empresas por semana, será posible cubrir 2500 empresas en las próximas 8 semanas. Hay que dar énfasis a las más grandes y las dirigidas a la exportación. Lo que es importante, en todo caso, es asegurar que los jerarcas del gobierno y los diputados no anden de paseo con el Presidente. Eso es una injustificable pérdida de tiempo y esfuerzo.

\section{Organizar un acto multitudinario de fuerza para darle motivación a la campaña}

Existe gran desmotivación entre quienes están a favor del TLC, desorientación por la ausencia de una campaña y, en muchos casos, miedo de expresar opiniones. Hay que motivar a los partidarios del SI, hacerles sentir que la campaña está haciendo cosas, que no están solos, que somos muchos. Es recomendable organizar un acto público o un festival multitudinario (podría ser una marcha, pero ahí casi siempre tenemos problemas). Pero la gente tiene que sentirse acompañada y motivada. 